\title{
EDITORIAL \\ Ipsilateral hemiparesis and its history for neurosurgery: same side, wrong side
}

\author{
Mark C. Preul, MD \\ The Loyal and Edith Davis Neurosurgical Research Laboratory, Department of Neurosurgery, Barrow Neurological Institute, St. \\ Joseph's Hospital and Medical Center, Phoenix, Arizona
}

$\mathrm{B}$ EGINNING in the 19th century, ideas regarding specifically localizing brain functions began to form and evolve. Within a century, intrepid approaches and investigations by such figures as John Hughlings Jackson, Pierre-Paul Broca, David Ferrier, Vladimir Betz, Korbinian Brodmann, Victor Horsley, Fedor Krause, Walter Dandy, and Wilder Penfield, among others, began to not only solidify descriptions of the localization of cerebral function but also demonstrate them on the open brain and correlate them with clinical and histological evidence. ${ }^{12,14}$ It was an era of the first craniocerebral topographic systems, developed to guide anatomical dissections of the brain and also to begin more precise brain surgery. ${ }^{15}$ Without brain imaging technology, of course, the location of a lesion still had to be determined on the basis of clinical examination findings, and on many occasions the presumed locus of the lesion indicated by the neurological signs did not match up with the true location that was eventually found. Krause would be the first neurosurgeon to significantly improve on this situation, with the first systematic use of radiographs in his patients, and Dandy would follow with ventriculography. ${ }^{5,7}$

Carrasco-Moro et al. ${ }^{3}$ provide a valuable and entertaining read about the historical problems of intracranial masses that caused focal neurological signs unrelated to the location of the lesion or mass, so-called "false localizing signs." The phenomenon of ipsilateral hemiparesis is one of the most well-known of such neurological situations, and even today ipsilateral hemiparesis is the subject of investigations of unusual clinical status correlated with modern brain-imaging techniques. The authors describe not only the main persons involved in the explanation of what became known as the "Kernohan-Woltman phenomenon," "Kernohan's notch phenomenon," or just "Kernohan's notch," but also the pathophysiological hypotheses formulated before and during the naming of this neuro- logical condition. The authors interestingly study publications or descriptions of ipsilateral hemiparesis from before the use of magnetic resonance imaging, so it is possible to review the assessment of and conclusions regarding ipsilateral hemiparesis from the origins of the concept through to the modern era. Carrasco-Moro et al. ${ }^{3}$ trace the conceptual evolution of ipsilateral hemiparesis associated with a brain lesion up to the 1970s. Such scrutiny of the original or primary sources is the key to the discovery of new information or revision of incomplete or incorrect conceptions regarding the mysteries of medical history, and it is just plain enjoyable, and often humbling, to read the original texts.

Carrasco-Moro et al. ${ }^{3}$ analyze the papers and philosophical approaches of the key individuals to describe an increasingly complex, but accurate, physiological and anatomical description of ipsilateral hemiparesis that involved the misconception that the condition is extremely rare. The authors educate the neurosurgery audience that the neurosurgical heritage of cerebral localization is not found only in Horsley, Cushing, Dandy, and Penfield; our expertise as surgical neurologists or neurological surgeons also harkens to Albert Pitres, Jean-Martin Charcot, Paul Flechsig, Charles-Édouard Brown-Séquard, Constantin von Monakow, Adolf Meyer, Albert Knapp, Arnold Groeneveld, and Georges Schaltenbrand. The individual who is perhaps of most interest to me, because of the institutional connection and his ingenuity, is James Kernohan, whose career was spent at the Mayo Clinic (1922-1961) and at Barrow Neurological Institute (1962-1964), and for whom the neurosurgical connection is made with ipsilateral hemiparesis. ${ }^{16}$

Kernohan made numerous contributions to general pathology, neuropathology, neurology, and neurosurgery. At the Mayo Clinic, he also worked closely with the renowned neurologist and neuropathologist Henry Wolt- 
man. They would publish a paper on the notching of the crus cerebri by the free tentorium, a phenomenon that later became widely known as Kernohan's notch. ${ }^{10,11}$ Kernohan and Woltman became intensely interested in James Collier (1870-1935) (although they did not cite his work), an assistant physician at the St. George's Hospital and the National Hospital for Nervous Disease, who reported his observations of patients with brain lesions who presented with "false localizing signs" during the years 1894 to 1904 , while he was working with the renowned neurologists Hughlings Jackson and Gordon Holmes. ${ }^{4}$ Collier wrote that "in many cases of supratentorial tumours the tentorium is pressed downwards. The medulla and posterior part of the cerebellum come to lie partly within the foramen magnum so that these structures together form a conical plug which fills up the foramen magnum. This alteration in the position of the brain may be also demonstrated post mortem by deep indentation of the crura cerebri by the free edge of the tentorium."'

In 1928, a year after a case publication by Groeneveld and Schaltenbrand, ${ }^{8}$ Kernohan and Woltman published their first case report on the "Incisura of the crus due to contralateral brain tumor," ${ }^{10}$ and subsequently, in 1929, they published a more detailed account of cases at the Mayo Clinic."1 They describe "notching" in 42 patients, with 7 showing marked clinical ipsilateral pyramidal signs, 17 with mild ipsilateral/false localizing signs (2 without notching), and 18 without clinical signs but who had notching. And yet, in what may be regarded as a closed case today, as Carrasco-Moro et al. ${ }^{3}$ ably describe, Kernohan and Woltman ${ }^{11}$ could not explain or corroborate the findings in some of their patients, but explained:

In eighteen cases, more or less, notching was not found; in these a survey of the corresponding histories did not disclose the presence of homolateral signs of the pyramidal tract on which we based our selection. In five of these cases, however, tendon reflexes were active on the same side as the lesion.

For the remaining discrepancies, we do not have an adequate explanation. ${ }^{11}$

Kernohan and Woltman suggested that vascular injury might be responsible, as opposed to a mechanical anatomical reason. However, they wrote, "It was necessary to remove the posterior cerebral and other subarachnoid arteries in this region (in autopsy) to see the notch...the grooves did not seem to be the result of arterial compression and none of the vessels was thrombosed."',9,11

Regardless of the etiology, ipsilateral/false localizing symptoms caused by compression of the contralateral cerebral peduncle by the tentorial edge have become eponymously identified with Kernohan. This phenomenon continues to lead to clinical confusion and misdiagnosis, with occasional reports of craniotomies performed on the incorrect side despite the use of modern imaging. ${ }^{18}$ As Carrasco-Moro et al. ${ }^{3}$ related, imaging and electrophysiological testing have been used to demonstrate compression or structural damage to the cerebral peduncle contralateral to a supratentorial lesion. Individual anatomical variation in the tentorial notch, along with the morphometric variations in the tentorial aperture and its regional anatomy may be associated with these different clinical presentations. ${ }^{1,2,17}$ The Kernohan notch phenomenon has even been used to explain putative general neurological or cognitive changes associated with ancient civilizations that performed intentional cranial deformation. ${ }^{13}$

The authors present an erudite and enjoyable description of a fascinating part of the history of cerebral functional localization that has been especially enduring and significant to the legacy of modern neurosurgery and the neurosurgical history of craniotomy.

https://thejns.org/doi/abs/10.3171/2019.6.FOCUS19501

\section{Acknowledgments}

The author is grateful for financial support from the Newsome Barrow-UK Chair in Neurosurgery Research and the Barrow Neurological Foundation. The author thanks the staff of Neuroscience Publications at Barrow Neurological Institute for expert assistance with manuscript preparation.

\section{References}

1. Adler DE, Milhorat TH: The tentorial notch: anatomical variation, morphometric analysis, and classification in 100 human autopsy cases. J Neurosurg 96:1103-1112, 2002

2. Binder DK, Lyon R, Manley GT: Transcranial motor evoked potential recording in a case of Kernohan's notch syndrome: case report. Neurosurgery 54:999-1003, 2004

3. Carrasco-Moro R, Castro-Dufourny I, Martínez-San Millán JS, Cabañes-Martínez L, Pascual JM: Ipsilateral hemiparesis: the forgotten history of this paradoxical neurological sign. Neurosurg Focus 47(3):E7, 2019

4. Collier J: The false localising signs of intracranial tumour. Brain 27:490-508, 1904

5. Dandy WE. Ventriculography following the injection of air into the cerebral ventricles. Ann Surg 68:5-11, 1918

6. Derakhshan I: The Kernohan-Woltman phenomenon and laterality of motor control: fresh analysis of data in the article "Incisura of the crus due to contralateral brain tumor." J Neurol Sci 287:296, 2009 (Letter)

7. Elhadi AM, Kalb S, Martirosyan NL, Agrawal A, Preul MC: Fedor Krause: the first systematic use of X-rays in neurosurgery. Neurosurg Focus 33(2):E4, 2012

8. Groeneveld A, Schaltenbrand G. Ein fall von dura endotheliom über der grobhirnhemisphäre mit einer bemerkenswerten komplikation: läison des gekreuzten pes pedunculi durch druck auf den rand des tentoriums. Dtsch Z Nervenheilkd 97:32-50, 1927

9. Hussain SI, Cordero-Tumangday C, Goldenberg FD, Wollman R, Frank JI, Rosengart AJ: Brainstem ischemia in acute herniation syndrome. J Neurol Sci 268:190-192, 2008

10. Kernohan JW, Woltman HW: Incisura of the crus due to contralateral brain tumor. Proc Staff Meetings Mayo Clinic 3:69-70, 1928

11. Kernohan JW, Woltman HW: Incisura of the crus due to contralateral brain tumor. Arch Neurol Psychiatry 21:274-287, 1929

12. Kushchayev SV, Moskalenko VF, Wiener PC, Tsymbaliuk VI, Cherkasov VG, Dzyavulska IV, et al: The discovery of the pyramidal neurons: Vladimir Betz and a new era of neuroscience. Brain 135:285-300, 2012

13. Lekovic GP, Baker B, Lekovic JM, Preul MC: New World cranial deformation practices: historical implications for pathophysiology of cognitive impairment in deformational plagiocephaly. Neurosurgery 60:1137-1147, 2007

14. Preul MC: A History of Neuroscience From Galen to Gall. Chicago: American Association of Neurological Surgeons, 1996

15. Reis CV, Sankar T, Crusius M, Zabramski JM, Deshmukh P, Rhoton AL Jr, et al: Comparative study of cranial topograph- 
ic procedures: Broca's legacy toward practical brain surgery. Neurosurgery 62:294-310, 2008

16. Safavi-Abbasi S, Maurer AJ, Archer JB, Hanel RA, Sughrue $\mathrm{ME}$, Theodore N, et al: From the notch to a glioma grading system: the neurological contributions of James Watson Kernohan. Neurosurg Focus 36(4):E4, 2014

17. Sunderland $\mathrm{S}$ : The tentorial notch and complications produced by herniations of the brain through that aperture. $\mathbf{B r} \mathbf{J}$ Surg 45:422-438, 1958

18. Wolf RF, ter Weeme CA, Krikke AP: Kernohan's notch and misdiagnosis. Lancet 345:259-260, 1995

\section{Disclosures}

The author reports no conflicts of interest.

\section{Correspondence}

Mark C. Preul: neuropub@barrowneuro.org.

INCLUDE WHEN CITING

DOI: 10.3171/2019.6.FOCUS19501. 